\title{
Can Plasma Donation Induce Coronary-Artery Thrombosis?
}

\author{
G Leurent ${ }^{1,2,3,4 *}$, M Bedossa ${ }^{1,2,3,4}$, C Camus ${ }^{5,6}$, N Behar ${ }^{1,2,3,4}$ and P Mabo Pa, $^{1,2,4}$ \\ ${ }^{1} \mathrm{CHU}$ Rennes, Service de cardiologie et maladies vasculaires, Rennes, F-35000, France \\ ${ }^{2}$ Université de Rennes 1, LTSI, Rennes, F-35000, France \\ IINSERM, U642, Rennes, F-35000, France \\ 4INSERM, CIC-IT 804, CHU de Rennes, F-35000, France \\ ${ }^{5} \mathrm{CHU}$ Rennes, Service de maladies infectieuses et réanimation médicale, Rennes, F-35000, France \\ ${ }^{6}$ INSERM, U835, Rennes, F-35000, France
}

\begin{abstract}
Plasmapheresis donation is supposed to be safe. However, we report the case of a 47-year old man without any cardiovascular risk factors or medical history, except being a large volume plasmapheresis donor. Twenty four hours after a plasmapheresis, he presented a sudden death due to an acute myocardial infarction caused by a thrombotic lesion. The only funded etiology of this arterial thrombosis is the recent plasmapheresis donation. Although this technique is known to be safe, this report is the third one published about a life threatening arterial thrombosis due to apheresis donation, raising the interrogation about it harmlessness.
\end{abstract}

Keywords: Plasmapheresis; Arterial thrombosis; Adverse effects; Acute coronary syndrome

\section{Introduction}

Plasmapheresis donation (PD) is reported to be a safe technique. However, our report of life-threatening coronary artery thrombosis raises interrogation about its harmlessness.

Case report: A 47-year old man was referred to our institution for an anterior acute myocardial infarction (MI) complicated by ventricular fibrillation (VF). The patient was a marathon runner without any cardiovascular risk factors, treatment or medical history, except being a large volume plasmapheresis donor (a total of 21 donations, including 5 in 2009). The last donation which occurred the day before MI was standard and apparently uncomplicated (sampling time: 48 minutes). The collected volume was $724 \mathrm{ml}$; anticoagulant $144 \mathrm{ml}$; device PCS $2{ }^{\circledR}$ (Haemonetics, Braintree, US); free interval from the precedent donation: 53 days. The patient received an oral compensation of $50 \mathrm{cl}$ of beverage, and rest for the day, as recommended in our institution.

Twelve hours after PD, the patient presented digestive discomfort followed by a sustained chest pain. Twelve hours later, he experienced sudden death related to VF. After a 45 min resuscitation, as the electrocardiogram showed anterior acute MI, the patient was given aspirin, clopidogrel, unfractionned heparin, and was transferred to our institution for a primary percutaneous coronary intervention (time from PD to balloon: 26 hours, from chest pain to balloon: 14 hours, from sudden death to balloon: 2 hours). The coronary angiography (Figure 1) showed a thrombotic subocclusion of the proximal left anterior descending artery (LAD), with a TIMI grade flow 2. Thromboaspiration was performed but, because of a persistent low flow, an angioplasty was necessary, with implantation of a bare metal stent. Final TIMI grade flow was 3 on the LAD (Figure 2 ) and no other lesion was noticed on the circumflex and right coronary arteries.

After the procedure, the patient presented with cardiogenic shock, rhythmic storm and multiple organ failure, requiring catecholamines and implantation of a circulatory assist device (extra corporeal membrane oxygenation) for 7 days.

After 6 weeks, trans thoracic echo showed a non dilated left ventricle with a large anteroapical akinesia with ejection fraction of $35 \%$. At 4 months, he had only minimal memory loss.

Blood test showed absence of diabetes, hypercholesterolemia, haemostasis abnormality, hyperhomocysteinemia and antiphospholipid syndrome. Metabolic balance at the admission was normal, as platelet count $\left(193.10^{9} /\right)$. Researches for vasculitis, heparin-induced thrombocytopenia and for thrombophilia was negative: antithrombin III: $109 \%$, protein C: $121 \%$, protein S: $87 \%$, absence of factor II or V (Leiden) mutation, absence of activated protein $\mathrm{C}$ resistance. No supra

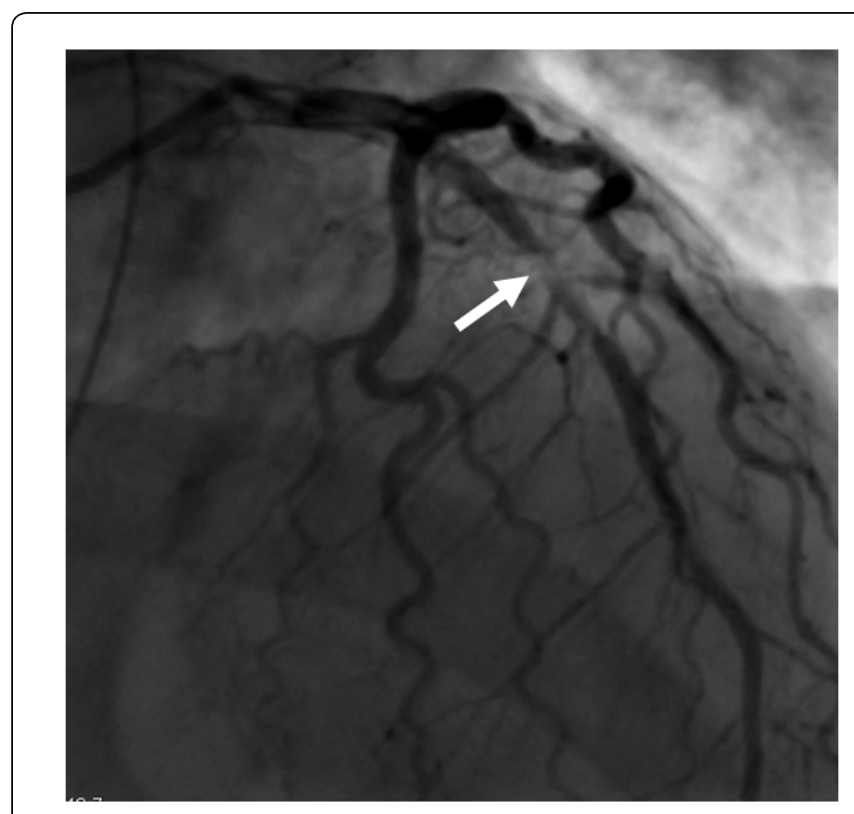

Figure 1: Initial coronary angiography showing a thrombotic subocclusion of the proximal left anterior descending artery (LAD).

*Corresponding author: Dr Guillaume Leurent, Service de cardiologie et maladies vasculaires, CHU de Rennes, Cedex 35033, Rennes, France, E-mail: guillaume. leurent@chu-rennes.fr

Received October 12, 2010; Accepted November 21, 2010; Published November 23, 2010

Citation: Leurent G, Bedossa M, Camus C, Behar N, Mabo P (2010) Can Plasma Donation Induce Coronary-Artery Thrombosis? J Blood Disord Transfus 1:103 doi:10.4172/2155-9864.1000103

Copyright: @ 2010 Leurent G, et al. This is an open-access article distributed unde the terms of the Creative Commons Attribution License, which permits unrestricted use, distribution, and reproduction in any medium, provided the original author and source are credited. 


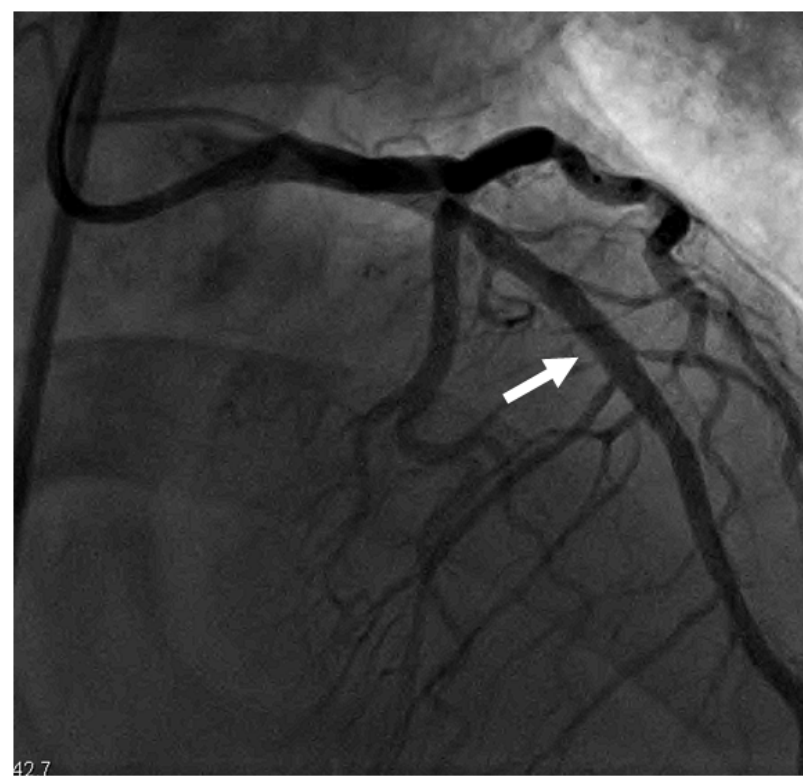

Figure 2: Coronary angiography after thromboaspiration and implantation of a stent.

ventricular arrhythmia was documented during the hospitalisation of the patient.

\section{Discussion}

PD is reported to be safe. Mostly reported adverse events are hypotensive or vasovagal episodes, pain or hematoma at venipuncture site. More severe events like thrombophlebitis or citrate toxicity are rare [1-6]. However, significant decrease in haemoglobin concentration, haematocrit, platelet and white blood cell counts after each procedure has been reported [7], with a significant increase in endogenous thrombopoietin, a key cytokine involved in the regulation of platelet production [8]. PD may also elongate prothrombin time [9], and decrease plasminogen levels [10], without any change in the plasma level of prothrombin fragment [11].

Nevertheless, the causal relationship to MI was possible, because of 1. time sequence of events (MI occurring 24 hours after PD); 2. mechanism of coronary occlusion (isolated thrombus without any atherosclerotic disease on the coronary angiogram); 3 . absence of other "usual" causes of MI, especially neither cardio vascular risk factors, haemostasis abnormalities, nor evidence for stress cardiomyopathy.

Several mechanisms can possibly explain arterial thrombosis in this circumstance: It has been shown that the platelets-derived growth factor (isoform $A B$ ) concentration was multiplied by a factor of 1.8 at the end of an apheresis for about an hour [12]. Apheresis may generate platelet activation with an increase of the surface expression of glycoproteins CD41a, CD42b, CD62p, and CD63, circulating for at least 48 hours following plasmapheresis $[13,14]$. It also causes a significant increase in platelet-neutrophil complex formation in donors with a decrease in CD62L expression which is a sign of mild neutrophil activation [15]. Furthermore, apheresis increases prothrombin fragment-F1 +2 , thrombin antithrombin III complex and fibrinopeptide A, causing a hypercoagulable state [16]. Finally, combined to the presence of activated platelets with platelet-leukocyte aggregates, hypovolemia may contribute to the hypercoagulable state, which might predispose certain donors to thrombotic complications following apheresis.
Two cases of arterial thrombosis have previously been reported. The first one concerned a 48-year old man who presented cerebral infarction 3 hours after a $1200 \mathrm{ml}$ plasma donation. Etiologic check-up revealed haemostasis anomalies (heterozygous for both methylene tetrahydrofolate reductase $677 \mathrm{c}-\mathrm{T}$ mutation and prothrombin 20210G-A allele) [17]. The second was an acute anterior MI immediately following platelet apheresis (total volume depletion: $663 \mathrm{ml}$ ) in a 57-year old donor, with a negative etiologic check-up. Nevertheless, in this second case, the infarction occurred 10 minutes after the apheresis and was preceded by a vaso-vagal reaction, so the hypothesis of a prolonged spasm cannot be eliminated [18].

Our case is the first one reporting arterial thrombosis which occurred after a 24-hour free interval following PD, without any other promoting factor, despite a regular hydratation. This raises interrogation about the harmlessness of apheresis donation.

\section{References}

1. McLeod BC, Price TH, Owen H, Ciavarella D, Sniecinski I, et al. (1998) Frequency of immediate adverse effects associated with apheresis donation Transfusion 38: 938-943.

2. Schulzki T, Seidel K, Storch H, Karges H, Kiessig S, et al. (2006) A prospective multicentre study on the safety of long-term intensive plasmapheresis in donors (SIPLA). Vox Sang 91:162-173.

3. Eder AF, Dy BA, Kennedy JM, Notari Iv EP, Strupp A, et al. (2008) The American Red Cross donor hemovigilance program: complications of blood donation reported in 2006. Transfusion 48:1809-1819.

4. Yuan S, Gornbein J, Smeltzer B, Ziman AF, Lu Q, et al. (2008) Risk factors for acute, moderate to severe donor reactions associated with multicomponent apheresis collections. Transfusion 48:1213-1219.

5. Jones DA, Williams E, Riley SA, Makris M (2002) Axillary vein thrombosis in a healthy donor following platelet apheresis. Br J Haematol 116: 390-391.

6. Bell AM, Nolen JD, Knudson CM, Raife TJ (2007) Severe citrate toxicity complicating volunteer apheresis platelet donation. J Clin Apher 22:15-16.

7. Das SS, Chaudhary R, Verma SK, Ojha S, Khetan D (2009) Pre- and postdonation haematological values in healthy donors undergoing plateletpheresis with five different systems. Blood Transfus 7:188-192.

8. Dettke M, Hlousek M, Kurz M, Leitner G, Rosskopf K, et al. (1998) Increase in endogenous thrombopoietin in healthy donors after automated plateletpheresis. Transfusion 38: 449-453.

9. Akay OM, Akin E, Mutlu F, Gulbas Z (2007) The effects of plateletpheresis on donor platelet function and coagulation. Transfus Apher Sci 37: 113-114.

10. Beyan C, Kaptan K, Savaşçi S, Ifran A (2005) Platelet apheresis affects prothrombin time and plasminogen levels in healthy donors. Transfus Apher Sci 38: 175-176.

11. Stohlawetz P, Kapiotis S, Seidl D, Hergovich N, Zellner M, et al. (1999) Safety issues of plateletpheresis: comparison of the effects of two cell separators on the activation of coagulation, fibrinolysis, and neutrophils and on the formation of neutrophil-platelet aggregates. Transfusion 39: 420-427.

12. Zimmermann R, Loew D, Weisbach V, Strasser E, Ringwald J, et al. (2005) Plateletpheresis does not cause long-standing platelet-derived growth factor release into the donor blood. Transfusion 45: 414-419.

13. Gutensohn K, Bartsch N, Kuehnl P (1997) Flow cytometric analysis of platele membrane antigens during and after continuous-flow plateletpheresis. Transfusion 37:809-15

14. Wun T, Paglieroni T, Holland P (1994) Prolonged circulation of activated platelets following plasmapheresis. J Clin Apher 9: 10-16.

15. Bilgin AU, Karadogan I, Yilmaz FG, Undar L (2007) Double dose plateletpheresis by continuous and intermittent flow devices increases platelet-neutrophil complex formation in healthy donors without noticeable neutrophil activation. Transfus Apher Sci 36: 31-37.

16. Kobayashi I, Hamaoka S, Ozawa H, Ihno M, Tamura K, et al. (1993) Hypercoagulable state induced by thrombocytapheresis. J Clin Apher 8: 147152.

17. Ovali E, Ratip S, Ozmenoglu M, Sami Karti S, Uçar F, et al. (2003) Large volume donor plasmapheresis in inherited thrombophilia implicated in arteria thrombosis. Transfus Apher Sci 28: 201-206.

18. Rosencher J, Zuily S, Varenne O, Spaulding C, Weber S (2010) Acute myocardial infarction secondary to platelet apheresis in a 57-year healthy donor. Int J Cardiol [Epub ahead of print]. 